\title{
Investigation Effect of Spring Back on Bending Test of (DP590) Dual Phase Steel
}

\author{
Muhamad Sani bin Buang ${ }^{I^{*}}$, Zalaida bt Talib ${ }^{1}$, Dr Norhayati bt. Zakaria ${ }^{l}$, Dr Shahrul Azam bin Abdullah ${ }^{2}$, \\ Hashim bin Abdullah ${ }^{3}$ \\ ${ }^{1}$ Politeknik Banting Selangor, Jalan Sultan Abdul Samad, 42700 Banting, Selangor, Malaysia. \\ ${ }^{2}$ Universiti Teknologi MARA, 40450 Shah Alam, Selangor, Malaysia. \\ ${ }^{3}$ Oriental Summit Industries Sdn. Bhd. Seksyen 28, 40400 Shah Alam, Selangor, Malaysia.
}

\begin{abstract}
The use of advanced high strength steels as a metal in sheet metal forming in automotive industry currently has been increased where Advanced High Strength Steel (AHSS) especially Dual Phase (DP590) Steels have gained a great attention due to a combination of high strength and good formability. However, one of the major constraints in forming AHSS is the occurrence of high spring back caused by elastic relaxation after loading, which causes illness-fitting in part assembly and geometric deviation of the intended design. Spring back is the main problem of defect that occurs at sheet metal after the bending process which creates problems for the parts during the assembly. This paper presents an investigation the effect of spring back on bending test of Dual Phase Steel (DP590). Punch travel and thickness are among factors affecting the spring back behavior. Various parameter value; punch radius $(5 \mathrm{~mm})$, die radius $(5 \mathrm{~mm})$, die gap $(70 \mathrm{~mm})$, thickness of specimen $1 \mathrm{~mm}$ and $2 \mathrm{~mm}$, punch travel/stroke $(25 \%, 50 \%, 75 \%, 100 \%)$ from $20 \mathrm{~mm}$ depth, punch speed $(2 \mathrm{~mm} / \mathrm{min})$ and Orientation of sheet cutting, which is in rolling $\left(00^{\circ}\right)$, diagonal $\left(45^{\circ}\right)$ and transverse $\left(90^{\circ}\right)$. From the analysis of V-bending test punch travel, thickness and orientation of sheet cutting are significant factor that affecting the spring back phenomena. The result form this experiment could be useful for design engineers and manufacturing engineers to make improvement of predict the spring back behavior and also to understanding the material properties of AHSS in order to eliminate spring back and achieve good final product.
\end{abstract}

Key words: DP590, Dual Phase Steel, Spring Back, Bending Test, Punch Travel, Orientation of Sheet

\section{INTRODUCTION}

Nowadays, popularity of lightweight material such as Advanced High Strength Steel (AHSS) greatly increases because of their characteristic and mechanical properties. In the automotive industry, demand of lightweight material, especially AHSS increase in order to produce a transport with higher fuel efficiency. Usually, AHSS used to make products such as the car components, body panels of a car, and the part of suspension. There a lot types of AHSS with different characteristic and properties such as Dual-phase Steel (DP), High Strength Low Alloy (HSLA) and etc.

Dual Phase Steel (DP) is one common lightweight material that's being used in automotive fabrication due to their best feature in physical and metallurgical properties compare to High Strength Low Alloy (HSLA). However, because of AHSS has better in strength, the formability and ductility become lower. Because of that the applications of AHSS become limited in automotive industry due to the problem of spring back [1]. Spring back is one of major defect that occur when the material has undergoes bending process, where the force bending has been release, the material try to return to original shape due to elastic recovery [24].

In the 1970, Dual-Phase Steel has been developed [5]. DP steels contains some alloy such as silicon or manganese [6]. The terms Dual Phase are because DP contains a ferrite matrix and a second phase of martensite [7]. Figure 1 indicates the schematic structure and microstructure of DP steel.

Corresponding Author: Muhamad Sani Bin Buang, Politeknik Banting Selangor, Jalan Sultan Abdul Samad, 42700 Banting, Selangor, Malaysia. 0166682002 


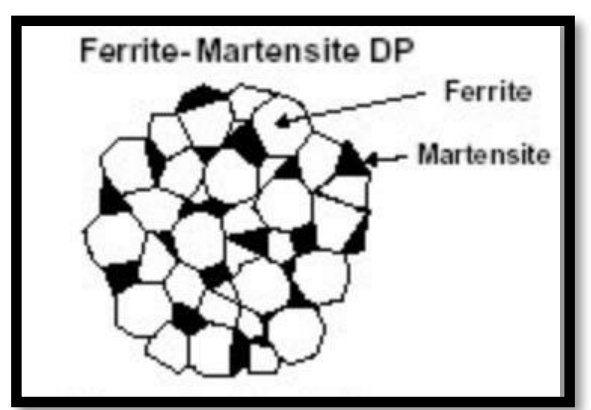

Figure 1: Schematic illustration of DP microstructure
There are two reasons that can lead to the spring back phenomena. The first reason is about the displacement of molecules within the material. The second reason is stress and strain [8]. When the material is bent, the inner region of the bend is compressed while the outer region is stretched and thus the molecular density is greater on the inside of the bend than on the outer surface. The reason the material return to its flat position is due to the tensile force that is greater than the compressive forces on the outside of the bend [9] which shown in figure 2 .

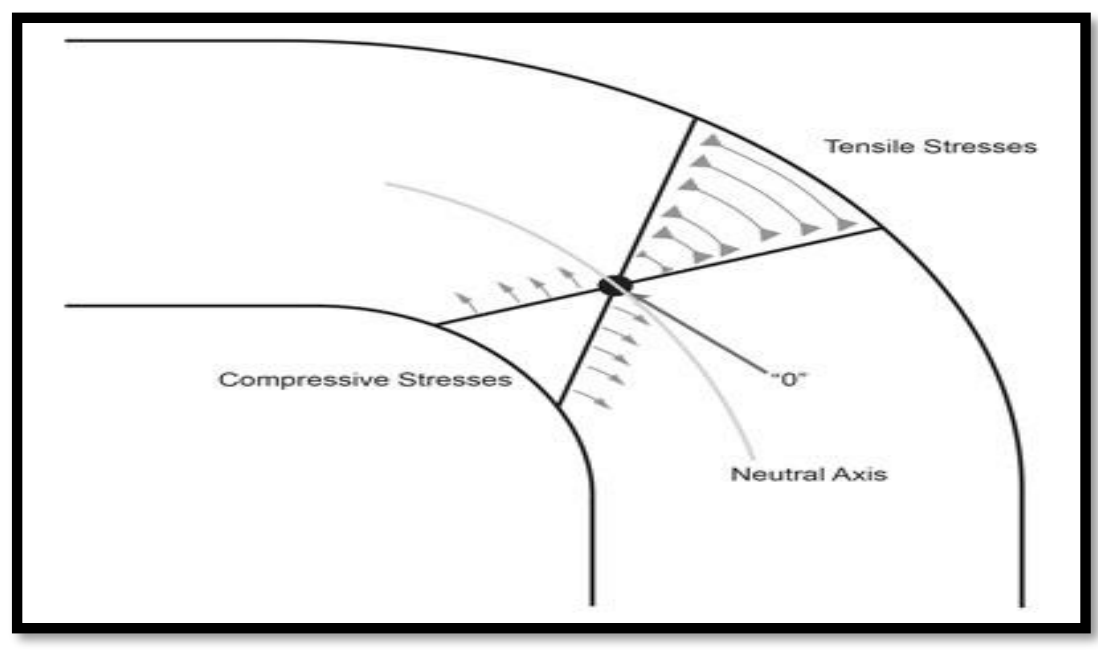

Figure 2: Bending undergoes a combination of compressive and tensile forces[10].

Tensile properties frequently are included material specifications to ensure quality. Tensile properties often are used to predict the behavior of a material under forms of loading than uniaxial tensions. The purpose of tensile testing in investigating spring back is to determine true stress-strain graph. Strain hardening, yield stress and elastic modulus are affected in spring back. The amount of spring back is depending on the ratio of yield stress to elastic modulus.

\section{EXPERIMENT}

Material preparation: In this investigation, the material that has chosen is Dual-Phase Steel (DP590), one of steel that categories on Advance High Strength Steel. There are two thicknesses that used in this project, first is $1 \mathrm{~mm}$ and second are 2mm. DP590 Steel has been cut based on rolling direction in rolling $\left(0^{\circ}\right)$, diagonal $\left(45^{\circ}\right)$ and transverse $\left(90^{\circ}\right)$.
Theory of Spring back: Basically, to measure the spring back, we need to refer to the theory of bending. The equation below shows how to calculate the angle of spring back .

$$
\Delta \theta=\theta_{i}-\theta_{f}
$$

$\Delta \theta \quad=$ angle of spring back

$\theta_{i} \quad=$ angle of loading

$\theta_{f} \quad=$ angle of unloading

The Figure 3 below shows how to measure the bending angle of V-bending during loading and unloading.

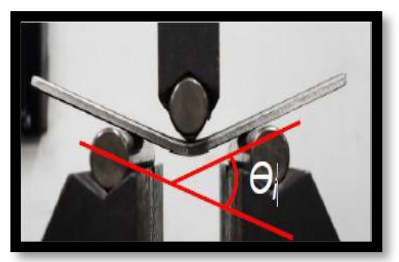

(a) 


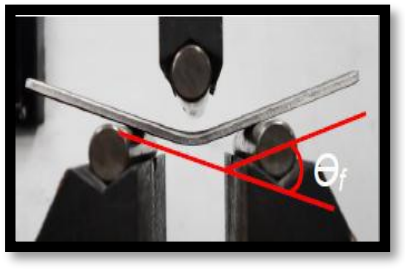

(b)

Figure 3: (a) angle during loading $\theta_{i}$, and (b) angle during unloading $\theta_{f} \cdot[11]$

\section{Bending Test.}

The specimen size of DP590 steel for Bending Test is $130 \mathrm{~mm} \times 30 \mathrm{~mm} \times$ thickness based on rolling direction $0^{\circ}, 45^{\circ}$ and $90^{\circ}$. There will be 3 specimens for each rolling direction $0^{\circ}, 45^{\circ}$ and 90 . The total for each thickness of specimen is 9 specimens for $1 \mathrm{~mm}$ and 9 specimens for $2 \mathrm{~mm}$. The total will be 18 specimens. The specimens will be undergoes cold V-bending test based on parameter that in Table 1.

Table 1: Parameter of V-Bending Test

\begin{tabular}{lc}
\hline Process parameter & Level \\
\hline Die radius (mm) & 5 \\
Punch Radius (mm) & 5 \\
Die Gap (mm) & 70 \\
Punch Velocity & 2 \\
(mm/min) & $130 \times 30$ \\
Size Specimen (mm) & 1 and 2 \\
Thickness (mm) & $0^{\circ}, 45^{\circ}, 90^{\circ}$ \\
Rolling Direction & $25 \%, 50 \%, 75 \%, 100 \%$ \\
Punch Travel & from 20 mm depth \\
\hline
\end{tabular}

\section{Procedure Before, During and After Process V-} Bending Test

Rolling direction of material DP590 with $0^{\circ}, 45^{\circ}$ and $90^{\circ}$ was determined. Specimen DP590 steel was cut using Hydraulic Cutter Machine. Size specimen 130mm x 30mm x thickness $1 \mathrm{~mm}$ and $2 \mathrm{~mm}$. 9 pieces DP590 steel are cut for $1 \mathrm{~mm}$ and 9 pieces for $2 \mathrm{~mm}$ as shown in Figure 4. Total specimens DP590 steel are 18 pieces.

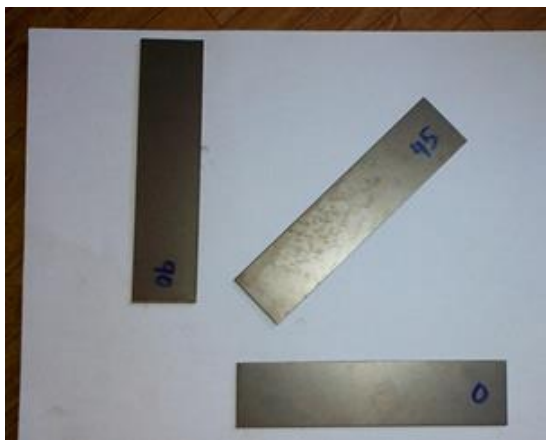

Figure 4: Specimen DP590 for V-Bending Test Steel that already cut based on rolling direction for $1 \mathrm{~mm}$ and $2 \mathrm{~mm}$.

V-bending test was performed using Universal Testing Machine are shown in Figure 5. V-bending test was set using parameter refer to Table 1. Picture was taken during loading and unloading process $\mathrm{V}$-bending to measure angle of spring back using camera.

Figure 6 shown the specimen DP590 has been done bending test. Data was recorded and generated using monitor that attach with Universal Testing System machine

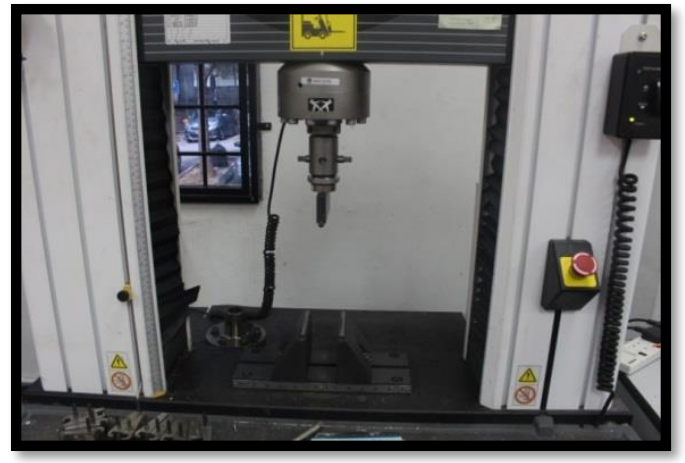

Figure 5: V-Bending was setup and waiting for testing.

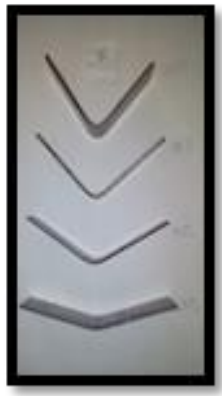

(a)

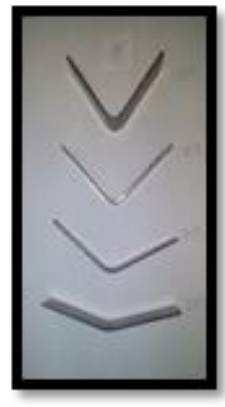

(b)

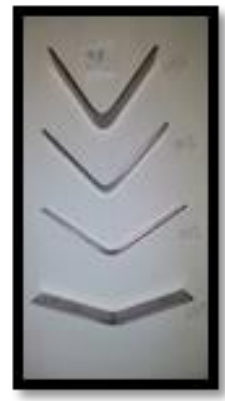

(c)
Figure 6: V-Bending specimen was done V-Bending process with rolling direction; a) 0 degree b) 45 degree c) 90 degree. 
The angle of spring back was measured and calculated by using two methods. First method was using Electronic Digital Protractor (for unloading) as shown in Figure 7. Meanwhile, CATIA V5R20 CAD software was used for the second method to measure the spring back angle (for loading) as shown in Figure 8.

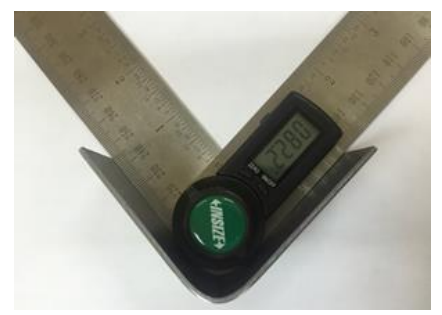

Figure 7: Angle of V-Bending specimen was measure by Electronic Digital Protractor (for unloading).

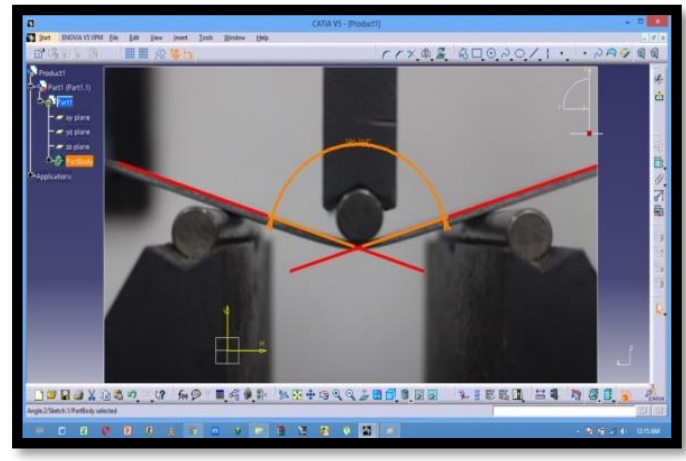

Figure 8: Measure angle of spring back using CATIA V5R20 CAD software (for loading).

Data of angle of loading and unloading was tabulate. Spring back was calculating using that data and analysis was carried out.

\section{RESULT AND DISCUSSION}

\section{Result For Bending Test:}

To obtain angle of loading and unloading two methods has been used. First method, the angle of unloading was measured manually by using Electronic Digital Protractor. Second method, the CAD software that is CATIA V5R20 was used to measured angle of loading. The result below had shown the angle of loading and unloading.

Result for Angle of V-Bending (unloading) (1mm) $00^{\circ}$ as shown in Table 2.
Table 2: Angle of V-Bending (unloading) using Electronic Digital Protractor.

\begin{tabular}{|c|c|c|c|c|}
\hline \multicolumn{5}{|c|}{ Sample DP590 (1mm) 00 degree } \\
\hline \multirow[b]{2}{*}{$\begin{array}{l}\text { Punch } \\
\text { loading }\end{array}$} & \multicolumn{4}{|c|}{ Result Reading (degree) } \\
\hline & $\begin{array}{c}\text { Specimen } \\
1\end{array}$ & $\begin{array}{c}\text { Specimen } \\
2\end{array}$ & $\begin{array}{c}\text { Specimen } \\
3\end{array}$ & Mean \\
\hline $0 \%$ & 0.0 & 0.0 & 0.0 & 0.0 \\
\hline $25 \%$ & 155.7 & 155.9 & 155.8 & 155.8 \\
\hline $50 \%$ & 129.2 & 129.1 & 129.3 & 129.2 \\
\hline $75 \%$ & 107.1 & 107.2 & 107.3 & 107.2 \\
\hline $100 \%$ & 90.5 & 90.6 & 90.7 & 90.6 \\
\hline
\end{tabular}

Result for Angle of V-Bending (loading) (1mm) $00^{\circ}$ as shown in Table 3.

Table 3: Angle of V-Bending (loading) using CATIA V5R20 software.

\begin{tabular}{cc}
\hline \multicolumn{2}{c}{ Sample DP590 $(1 \mathrm{~mm})$ 00 degree } \\
\hline Sample & Reading (Degree) \\
$0 \%$ & 0.00 \\
$25 \%$ & 140.36 \\
$50 \%$ & 110.69 \\
$75 \%$ & 86.48 \\
$100 \%$ & 68.14 \\
\hline
\end{tabular}

Result for Angle of V-Bending (unloading) DP590 (1mm) $45^{\circ}$ as shown in Table 4 .

Table 4: Angle of V-Bending (unloading) using Electronic Digital Protractor.

\begin{tabular}{ccccc}
\hline \multicolumn{5}{c}{ Sample DP590 (1mm) 45 degree } \\
\hline Punch & \multicolumn{4}{c}{ Result Reading (degree) } \\
loading & Specimen & Specimen & Specimen & mean \\
$0 \%$ & 1 & 2 & 3 & \\
$25 \%$ & 0.0 & 0.0 & 0.0 & 0.0 \\
$50 \%$ & 156.4 & 156.6 & 156.5 & 156.5 \\
$75 \%$ & 128.7 & 128.8 & 128.6 & 128.7 \\
$100 \%$ & 90.5 & 107.4 & 107.3 & 107.3 \\
\hline
\end{tabular}


Result for Angle of V-Bending (loading) DP590 (1mm) $45^{\circ}$ as shown in Table 5.

Table 5: Angle of V-Bending (loading) using CATIA V5R20 software

\begin{tabular}{cc}
\hline \multicolumn{2}{c}{ Sample DP590 $(1 \mathrm{~mm}) 45$ degree } \\
\hline Sample & Reading (Degree) \\
$0 \%$ & 0.00 \\
$25 \%$ & 139.71 \\
$50 \%$ & 109.25 \\
$75 \%$ & 86.06 \\
$100 \%$ & 67.81 \\
\hline
\end{tabular}

Result for Angle of V-Bending (unloading) DP590 (1mm) $90^{\circ}$ as shown in Table 6 .

Table 6: Angle of V-Bending (unloading) using Electronic Digital Protractor.

\begin{tabular}{ccccc}
\hline \multicolumn{5}{c}{ Sample DP590 (1mm) 90 degree } \\
\hline Punch & \multicolumn{4}{c}{ Result Reading (degree) } \\
loading & Specimen & Specimen & Specimen & mean \\
& 1 & 2 & 3 & \\
$0 \%$ & 0.0 & 0.0 & 0.0 & 0.0 \\
$25 \%$ & 158.6 & 158.4 & 158.5 & 158.5 \\
$50 \%$ & 130.3 & 130.4 & 130.5 & 130.4 \\
$75 \%$ & 108.2 & 108.0 & 108.1 & 108.1 \\
$100 \%$ & 91.3 & 91.2 & 91.4 & 91.3 \\
\hline
\end{tabular}

Result for Angle of V-Bending (loading) DP590 (1 mm) $90^{\circ}$ as shown in Table 7.

Table 7: Angle of V-Bending (loading) using CATIA

\begin{tabular}{cc}
\multicolumn{2}{c}{ V5R20 software } \\
\hline Sample DP590 (1mm) 90 degree \\
\hline Sample & Reading (Degree) \\
$0 \%$ & 0.00 \\
$25 \%$ & 140.56 \\
$50 \%$ & 110.06 \\
$75 \%$ & 86.05 \\
$100 \%$ & 68.00 \\
\hline
\end{tabular}

Result for Angle of V-Bending (unloading) DP590 (2mm) $00^{\circ}$ as shown in Table 8 .
Table 8: Angle of V-Bending (unloading) using Electronic Digital Protractor.

\begin{tabular}{ccccc}
\hline \multicolumn{5}{c}{ Sample DP590 (2mm) 00 degree } \\
\hline $\begin{array}{c}\text { Punch } \\
\text { loading }\end{array}$ & \multicolumn{4}{c}{ Result Reading (degree) } \\
& Specimen 1 & Specimen & Specimen & mean \\
$\mathbf{0 \%}$ & 0.0 & 0.0 & 0.0 & 0.0 \\
$\mathbf{2 5 \%}$ & 153.0 & 153.2 & 153.1 & 153.1 \\
$\mathbf{5 0 \%}$ & 123.8 & 123.7 & 123.6 & 123.7 \\
$\mathbf{7 5 \%}$ & 99.7 & 99.8 & 99.6 & 99.7 \\
$\mathbf{1 0 0 \%}$ & 82.0 & 81.9 & 82.1 & 82.0 \\
\hline
\end{tabular}

Result for Angle of V-Bending (loading) DP590 (2mm) $00^{\circ}$ as shown in Table 9.

Table 9: Angle of V-Bending (loading) using CATIA

\begin{tabular}{cc}
\multicolumn{2}{c}{ V5R20 software } \\
\hline Sample DP590 $(2 \mathrm{~mm})$ 00 degree \\
\hline Sample & Reading (Degree) \\
$\mathbf{0 \%}$ & 0.00 \\
$\mathbf{2 5 \%}$ & 144.76 \\
$\mathbf{5 0 \%}$ & 113.75 \\
$\mathbf{7 5 \%}$ & 87.78 \\
$\mathbf{1 0 0 \%}$ & 69.02 \\
\hline
\end{tabular}

Result for Angle of V-Bending (unloading) DP590 (2mm) $45^{\circ}$ as shown in Table 10.

Table 10: Angle of V-Bending (unloading) using Electronic Digital Protractor.

\begin{tabular}{ccccc}
\hline \multicolumn{5}{c}{ Sample DP590 (2mm) 45 degree } \\
\hline $\begin{array}{c}\text { Punch } \\
\text { loading }\end{array}$ & \multicolumn{4}{c}{ Result Reading (degree) } \\
& Specimen 1 & Specimen & Specimen & mean \\
$0 \%$ & 0.0 & 0.0 & 0.0 & 0.0 \\
$25 \%$ & 153.0 & 153.1 & 153.2 & 153.1 \\
$50 \%$ & 122.8 & 122.9 & 123.0 & 122.9 \\
$75 \%$ & 99.1 & 99.0 & 98.6 & 98.9 \\
$100 \%$ & 81.3 & 81.4 & 81.2 & 81.3 \\
\hline
\end{tabular}

Result for Angle of V-Bending (loading) DP590 (2mm) $45^{\circ}$ as shown in Table 11 . 
Table 11: Angle of V-Bending (loading) using CATIA V5R20 software

\begin{tabular}{cc}
\hline \multicolumn{2}{c}{ Sample DP590 $(2 \mathrm{~mm}) 45$ degree } \\
\hline Sample & Reading (Degree) \\
$\mathbf{0 \%}$ & 0.00 \\
$\mathbf{2 5 \%}$ & 144.16 \\
$\mathbf{5 0 \%}$ & 112.62 \\
$\mathbf{7 5 \%}$ & 86.84 \\
$\mathbf{1 0 0 \%}$ & 68.06 \\
\hline
\end{tabular}

Result for Angle of V-Bending (unloading) DP590 (2mm) $90^{\circ}$ as shown in Table 12 .

Table 12: Angle of V-Bending (unloading) using Electronic Digital Protractor.

\begin{tabular}{ccccc}
\hline \multicolumn{5}{c}{ Sample DP590 (2mm) 90 degree } \\
\hline $\begin{array}{c}\text { Punch } \\
\text { loading }\end{array}$ & \multicolumn{4}{c}{ Result Reading (degree) } \\
& Specimen 1 & Specimen & Specimen & mean \\
$0 \%$ & 0.0 & 0.0 & 0.0 & 0.0 \\
$25 \%$ & 152.8 & 152.9 & 153.0 & 152.9 \\
$50 \%$ & 123.1 & 123.2 & 123.0 & 123.1 \\
$75 \%$ & 99.5 & 99.3 & 99.4 & 99.4 \\
$100 \%$ & 81.5 & 81.4 & 81.6 & 81.5 \\
\hline
\end{tabular}

Result for Angle of V-Bending (loading) DP590 (2mm) $90^{\circ}$ as shown in Table 13.

Table 13: Angle of V-Bending (loading) using CATIA V5R20 software

\begin{tabular}{cc}
\hline Sample DP590 (2mm) & 90 degree \\
\hline Sample & Reading (Degree) \\
$0 \%$ & 0.00 \\
$25 \%$ & 143.57 \\
$50 \%$ & 112.19 \\
$75 \%$ & 86.63 \\
$100 \%$ & 67.85 \\
\hline
\end{tabular}

\section{Result Angle of Spring back}

The angle of spring back was obtain by using equation and was tabulate as shows in Table below.

$$
\Delta \theta_{\text {springback }}=\theta_{\text {unloading }}-\theta_{\text {loading }}
$$

Result Angle of spring back for thickness $1 \mathrm{~mm}$ DP590 steel for $00^{\circ}, 45^{\circ}$ and $90^{\circ}$ as shown in Table 14 until 16.

Table 14: The angle of spring back for sample $(1 \mathrm{~mm}) 00$ degree

\begin{tabular}{cccc}
\hline \multicolumn{4}{c}{ Sample DP590 (1mm) 00 degree } \\
\hline $\begin{array}{c}\text { Punch } \\
\text { loading }\end{array}$ & Lngle (Degree) \\
$0 \%$ & 0.00 & 0.00 & 0.00 \\
$25 \%$ & 140.36 & 155.80 & 15.44 \\
$50 \%$ & 110.69 & 129.20 & 18.51 \\
$75 \%$ & 86.48 & 107.20 & 20.72 \\
$100 \%$ & 68.14 & 90.60 & 22.46 \\
\hline
\end{tabular}

Table 15: The angle of spring back for sample (1mm) 45 degree

\begin{tabular}{cccc}
\hline \multicolumn{4}{c}{ Sample DP590 (1mm) 45 degree } \\
\hline $\begin{array}{c}\text { Punch } \\
\text { loading }\end{array}$ & Loading & Unloading & $\begin{array}{c}\text { Spring } \\
\text { back }\end{array}$ \\
$0 \%$ & 0.00 & 0.00 & 0.00 \\
$25 \%$ & 139.71 & 156.50 & 16.79 \\
$50 \%$ & 109.25 & 128.70 & 19.45 \\
$75 \%$ & 86.06 & 107.30 & 21.24 \\
$100 \%$ & 67.81 & 90.50 & 22.69 \\
\hline
\end{tabular}

Table 16: The angle of spring back for sample (1mm) 90 degree

\begin{tabular}{cccc}
\hline \multicolumn{4}{c}{ Sample DP590 (1mm) 90 degree } \\
\hline $\begin{array}{c}\text { Punch } \\
\text { loading }\end{array}$ & Loading & Ungle (Degree) \\
$0 \%$ & 0.00 & 0.00 & 0.00 \\
$25 \%$ & 140.56 & 158.50 & 17.94 \\
$50 \%$ & 110.06 & 130.40 & 20.34 \\
$75 \%$ & 86.05 & 108.10 & 22.05 \\
$100 \%$ & 68.00 & 91.30 & 23.30 \\
\hline
\end{tabular}

Result Angle of spring back for thickness $\mathbf{2 m m}$ DP590 steel for $00^{\circ}, 45^{\circ}$ and $90^{\circ}$ as shown in Table 17 until 19. 
Table 17: The angle of spring back for sample (2mm) 00 degree

\begin{tabular}{cccc}
\hline \multicolumn{4}{c}{ Sample DP590 (2mm) 00 degree } \\
\hline $\begin{array}{c}\text { Punch } \\
\text { loading }\end{array}$ & Loading & Angle (Degree) \\
$0 \%$ & 0.00 & 0.00 & 0.00 \\
$25 \%$ & 144.76 & 153.10 & 8.34 \\
$50 \%$ & 113.75 & 123.70 & 9.95 \\
$75 \%$ & 87.78 & 99.70 & 11.92 \\
$100 \%$ & 69.02 & 82.00 & 12.98 \\
\hline
\end{tabular}

Table 18: The angle of spring back for sample

\begin{tabular}{cccc}
\multicolumn{4}{c}{$(2 \mathrm{~mm}) 45$ degree } \\
\hline $\begin{array}{c}\text { Punch } \\
\text { loading }\end{array}$ & Loading & Angle (Degree) \\
$\mathbf{0 \%}$ & 0.00 & 0.00 & 0.00 \\
$\mathbf{2 5 \%}$ & 144.16 & 153.10 & 8.94 \\
$\mathbf{5 0 \%}$ & 112.62 & 122.90 & 10.28 \\
$\mathbf{7 5 \%}$ & 86.84 & 98.90 & 12.06 \\
$\mathbf{1 0 0 \%}$ & 68.06 & 81.30 & 13.24 \\
\hline
\end{tabular}

Table 19: The angle of spring back for sample (2mm) 90 degree

\begin{tabular}{cccc}
\hline \multicolumn{4}{c}{ Sample DP590 (2mm) 90 degree } \\
\hline $\begin{array}{c}\text { Punch } \\
\text { loading }\end{array}$ & Loading & Ungle (Degree) \\
$\mathbf{0 \%}$ & 0.00 & 0.00 & Spring back \\
$\mathbf{2 5 \%}$ & 143.57 & 152.90 & 9.00 \\
$\mathbf{5 0 \%}$ & 112.19 & 123.10 & 10.91 \\
$\mathbf{7 5 \%}$ & 86.63 & 99.40 & 12.77 \\
$\mathbf{1 0 0 \%}$ & 67.85 & 81.50 & 13.65 \\
\hline
\end{tabular}

\section{Discussion}

Effect of the various parameters on spring back was plotted at various punch travel on the graph and illustrated.

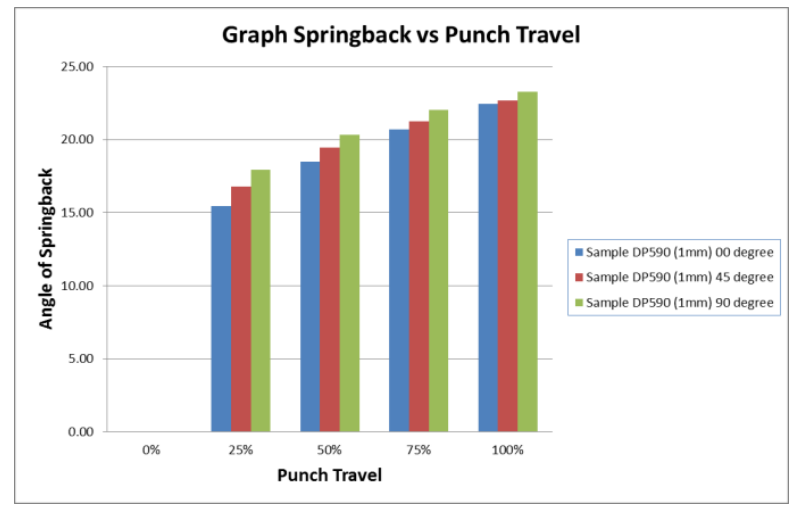

Figure 9: Graph Spring back vs Punch Travel for DP590 for thickness $1 \mathrm{~mm}$

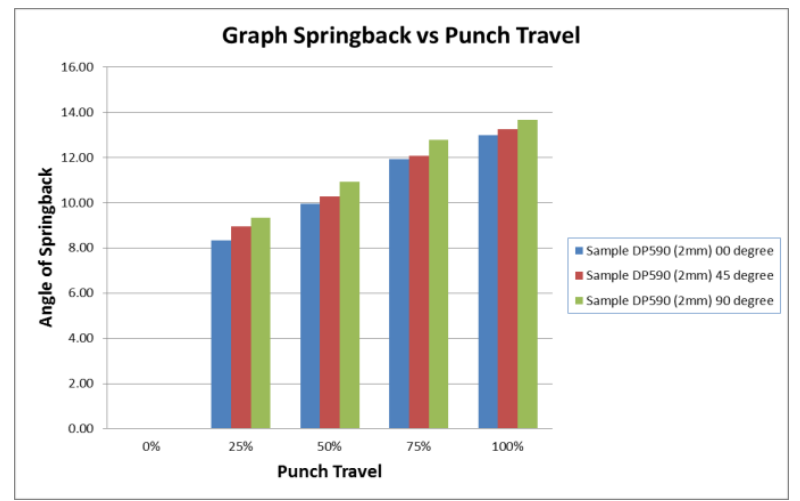

Figure 10: Graph Spring back vs Punch Travel for DP590 for thickness $2 \mathrm{~mm}$

Effect of Punch Travel on Spring Back Angle

Figure 09 and Figure 10, shown the effect of punch travel on spring back. It was observed with the increase of punch travel from $25 \%$ to $100 \%$, spring back was increasing for all thicknesses. It was also observed with the increase of DP590 steel thickness, spring back was increasing for all punch travels.

\section{Effect of Orientation}

From the observation on the graph also shown, the value of spring back was different when rolling direction was different at $0^{\circ}, 45^{\circ}$ and $90^{\circ}$ orientations. The higher the angle of rolling direction the higher the spring back values will happen. 


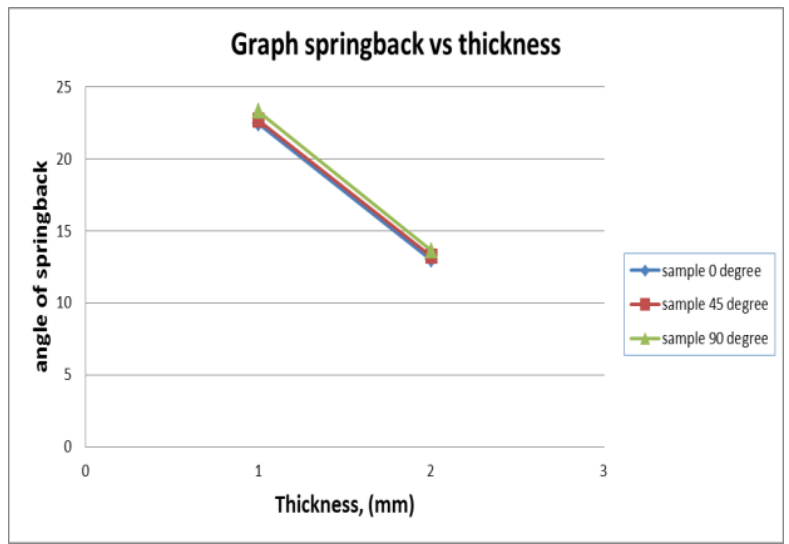

Figure 11: Graph of springback vs Thickness

\section{Effect of Thickness}

The thickness material also influence to value of spring back. Figure 11 shows the influence of thickness to spring back. From the graph, when the thickness was increase the value of spring back also increase. In order to reduce the spring back the thickness, punch travel and rolling direction need to consider to better final product.

\section{CONCLUSION}

Based on the investigations effect of spring back on bending test of DP590 Dual Phase steel, following conclusions are drawn;

- In the case of bending along rolling direction, $90^{\circ}$ orientation, spring back is more for DP590 Dual Phase Steel for each punch travel or band angle, as compare to bending across rolling direction, $0^{\circ}$ and $45^{\circ}$ orientation.

- Spring back is more in the case of DP590 Dual Phase Steel Sheet in thickness. Spring back increases with the increase of DP590 steel sheet thickness.

- With the increase of punch travel, bend angle increases, and with the increase of bend angle, spring back increases for DP590 Dual Phase Steel Sheet.

\section{ACKNOWLEDGMENTS}

The authors would like to thank to the Polytechnic Banting Selangor, and Minister of Education Malaysia, Ministry of Science, Technology and Innovation Malaysia (MOSTI) for financial support under the eScience Fund Project Grant No: 100-RMI/SF 16/6/2 (5/2014). A special thank is addressed to Faculty of Mechanical Engineering, University Technology MARA (UiTM) Shah Alam, Special thank also goes to an automobile industry, Oriental Summit Industries Sdn.
Bhd. Shah Alam, Selangor for the permission and cooperation in this study.

\section{REFERENCES}

[1] Chen, P., M. Koç, and M.L. Wenner, Experimental investigation of springback variation in forming of high strength steels. Journal of manufacturing science and engineering, 2008. 130(4): p. 041006.

[2] Chikalthankar, S.B., G.D. Belurkar, and V.M. Nandedkar, Factors Affecting on Springback in Sheet Metal Bending: A Review. International Journal of Engineering and Advanced Technology 2014. Volume-3(Issue-4): p. 247-251.

[3] Jiang, H.-J. and H.-L. Dai, A novel model to predict $U$-bending springback and time-dependent springback for a HSLA steel plate. The International Journal of Advanced Manufacturing Technology, 2015.

[4] Lepadatu, D., et al., Optimisation of springback in bending processes using FEM simulation and response surface method. The International Journal of Advanced Manufacturing Technology, 2005. 27(1-2): p. 40-47.

[5] Kim, H., M. Kimchi, and T. Altan, Control of Springback in Bending and Flanging Advanced High Strength Steels (AHSS). International Automotive Body Congress (IABC), 2009.

[6] Bleck, W., Cold-rolled, high-strength sheet steels for auto applications. JOM, 1996. 48(7): p. 26-30.

[7] Huang, Y.-M. and D.-K. Leu, Effects of process variables on V-die bending process of steel sheet. International Journal of Mechanical Sciences, 1998. 40(7): p. 631-650.

[8] Yamaguchi, K., H. Adachi, and N. Takakura, Effects of plastic strain and strain path on youngs modulus of sheet metals. Metals and Materials, 1998. 4(3): p. 420-425.

[9] Slota, J., M. Jurčišin, and E. Spišák, Numerical And Experimental Springback Determination Of Sheet Metals In An Air Bending Process. Acta Metallurgica Slovaca, 2012. 18(4): p. 200-209.

[10] Associates, S., Bending Of Metals Including " $V$ ", Wipe And Rotary Die Operations, ed. -. C040. 2005, Hollywood Drive, Monroe, Michigan.

[11] Buang, M.S., S.A. Abdullah, and J. Saedon, Effect of Die Gap and Punch Travel on Springback in Air V-Bending Process Using Taguchi Method. Applied Mechanics and Materials, 2014. 660: p. 317-321. 